\title{
Utilization of Double Random Phase Encoding for Securing Color Images
}

\author{
Mohammed A. AlZain \\ College of Computers and Information Technology \\ Taif University, P.O. Box 888 \\ Al-Hawiya-Taif, 21974, KSA
}

\begin{abstract}
This paper investigates the Double Random Phase Encoding (DRPE) implementation in encrypting color digital images. The color optical image cipher works through splitting color plainimage into red $(\mathrm{R})$, green $(\mathrm{G})$ and blue $(\mathrm{B})$ channels. The color plainimage RGB components are multiplied with the random phase mask (RPM) and transformed with Fourier Transform (FT). The modulated RGB components are again multiplied using the second RPM and subjected again to inverse FT. A set of experimental tests using different color images has been employed to study the security of DRPE for encrypting digital color images. Experimental results demonstrated the efficiency of DRPE for encrypting digital color images and its immunity regarding the most potential attacks.
\end{abstract}

\section{General Terms}

Security, Image Encryption.

\section{Keywords}

DRPE, Fourier Transform (FT), Color image encryption

\section{INTRODUCTION}

The optical cryptography methods have significant impact on the optical information processing field. Efficient and dependable security methods in transmitting and storing digital images are required for several applications such as video conferencing, pay TVs, medical images storing and transmission, military usage, police identification, online banking, and governmental systems.

The Opto-security schemes have gained a lot of advances because of their features of parallel processing and fast processing. The Optics offers several freedom degrees in optical beams can be modulated, like as the phase, amplitude, wavelength, and polarization. So, many optical encryption schemes have been introduced [1-4].

The DRPE presented in [5], may be considered the most commonly utilized optical encryption method. The Fractional Fourier transform (FrFT) was introduced as generalization for traditional encryption [6-7]. The Fourier Transform (FT) is commonly utilized in optical image encryption [8-10].

The optical DRPE color image encryption begins with splitting color plainimage into RGB components that modulated by the first RPM and FT transformed. The achieved RGB channels are secondly modulated using another RPM and again FT transformed.

The paper remainder is appeared as follows. Sec. 2 gives the main fundamentals regarding DRPE. Sect. 3 presents encryption/decryption stages. Sect. 4 gives the security study of the optical DRPE encryption. And conclusions are given in Sect. 5 .

\section{DRPE FUNDAMENTALS}

The DRPE depends on modifying the image spectral allocation regardless information of spectral alternation or received image in receiving side. The basic is based on putting two RPM (encoding secret keys) in setup named $4 \mathrm{f}$. The DRPE encryption can be defined as [5]:

$Y(a, b)=F T\{F T[X(a, b) \exp (j 2 \pi \theta(a, b))] \exp (j 2 \pi \omega(u, v))\}$ 1

The DRPE decryption can be defined as [5]:

$X(a, b)=\left\{F T^{-1}\left[F T^{-1}(Y(a, b)) \exp (-j 2 \pi \omega(u, v))\right\} \exp (-j 2 \pi \theta(a, b))\right.$ 2

The $\exp (j 2 \pi \theta(x, y))$ and $\exp (-j 2 \pi \omega(u, v))$ represent two RPM secret keys which will be transmitted with the encrypted color image. FT/FT -1 represents the Fourier and inverse Fourier transformations.

\section{THE OPTICAL DRPE FOR COLOR IMAGE ENCRYPTION}

The encryption/decryption stages using DRPE encryption are listed below in the next two subsections, respectively.

\subsection{Encryption Stage}

The color plainimage $I\left(x_{i}, y_{j}\right)$ is split into R, G, and B component as $I_{R}\left(x_{i}, y_{j}\right), I_{G}\left(x_{i}, y_{j}\right)$ and $I_{G}\left(x_{i}, y_{j}\right)$, respectively. Each of RGB components is multiplied using the first $R P M_{r 1}\left(x_{i}, y_{j}\right), R P M_{g 1}\left(x_{i}, y_{j}\right)$, and $R P M_{b 1}\left(x_{i}, y_{j}\right)$, and perform $F T$. The transformed $\mathrm{R}, \mathrm{G}$, and $\mathrm{B}$ components are multiplied with the second $R P M_{r 2}\left(u_{i}, v_{j}\right), R P M_{g_{2}}\left(u_{i}, v_{j}\right)$ and $R P M_{b 2}\left(u_{i}, v_{j}\right)$, and then employed second $F T$. The three encrypted R, G, and $\mathrm{B}$ components $E_{r 2}\left(x_{i}, y_{j}\right), \quad E_{g 2}\left(x_{i}, y_{j}\right)$ and $E_{b 2}\left(x_{i}, y_{j}\right)$ are multiplexed to obtain the encrypted color image $E\left(x_{i}, y_{j}\right)$.

\subsection{Decryption Stage}

The encrypted color image $E\left(x_{i}, y_{j}\right)$ is split into R/G/B components $E_{r}\left(x_{i}, y_{j}\right), E_{g}\left(x_{i}, y_{j}\right)$ and $E_{b}\left(x_{i}, y_{j}\right)$, respectively. The $F T^{-1}$ is applied to color $\mathrm{R} / \mathrm{G} / \mathrm{B}$ components, and modulated using $R P M_{r 2}^{*}\left(u_{i}, v_{j}\right), \operatorname{RPM}_{g 2}^{*}\left(u_{i}, v_{j}\right), \quad$ and $R P M_{b 2}^{*}\left(u_{i}, v_{j}\right)$. Another $F T^{-1}$ is applied to modulated R/G/B components and modulated with $R P M_{r 1}^{*}\left(x_{i}, y_{j}\right), \operatorname{RPM}_{g 1}^{*}\left(x_{i}, y_{j}\right)$ and $R P M_{b 1}^{*}\left(x_{i}, y_{j}\right)$. The decrypted R/G/B components $B_{r 2}\left(x_{i}, y_{j}\right), B_{g 2}\left(x_{i}, y_{j}\right)$ and $B_{b 2}\left(x_{i}, y_{j}\right)$ are assembled to get the final decrypted color image $D\left(x_{i}, y_{j}\right)$.

\section{SIMULATION EXPERIMENT}

Several tests are carried out for studying the efficiency of the optical DRPE for color image encryption. The performance of optical DRPE for color image encryption is performed using 
several encryption performance metrics such as visually inspection, entropy estimation, statistical evaluation, differential measures, quality estimation, and noise immunity. Tests were performed using three $256 \times 256$ color Lena, House, and House images. The original test plainimages are illustrated in Fig. 1.

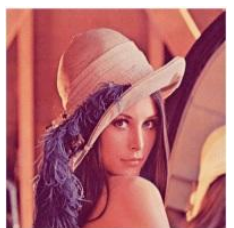

a) Lena

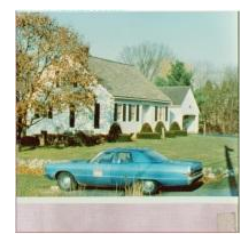

b) House

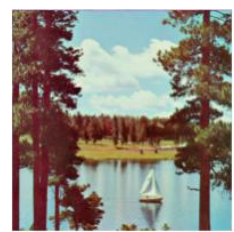

c) Sailboat

Fig. 1: Color plainimages - Lena, House, and House

\subsection{Visual Quality Inspection}

The efficiency of DRPE is investigated in encrypting color Lena, House and Sailboat images. The encryption results of optical DRPE are depicted in Fig. 2 for color Lena, House and Sailboat images. The obtained test consequences for encrypted color Lena, House and Sailboat images ensure the superiority of optical DRPE in hiding all features of their corresponding color plainimages.

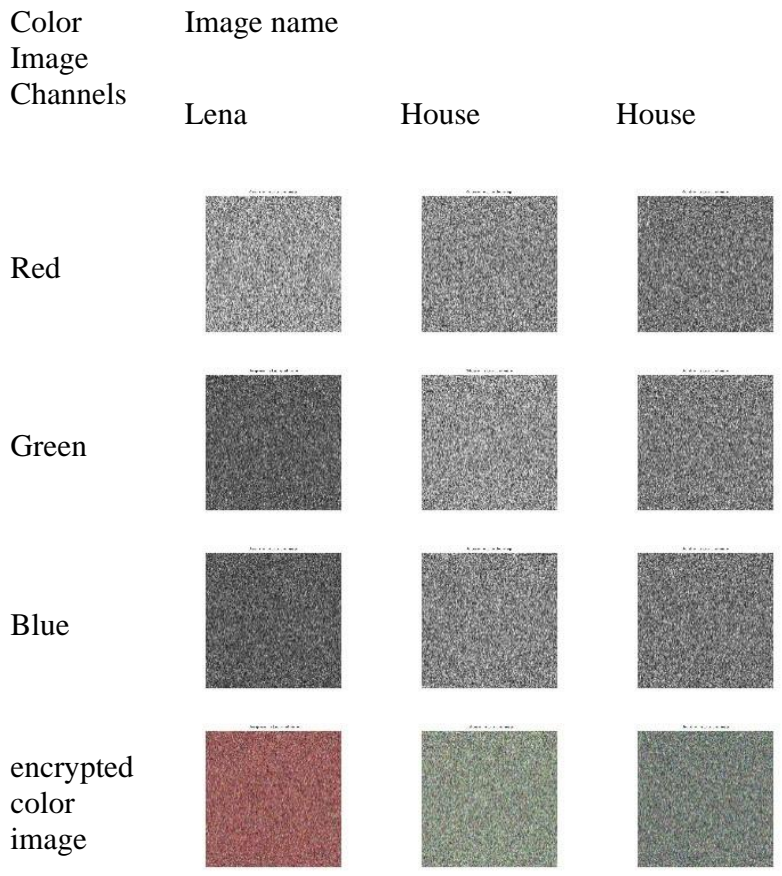

Fig. 2: Encrypted color Lena, House and Sailboat color image components using optical DRPE

\subsection{Histogram Test}

The histogram test for is a graph which show the pixels number for each intensity value. The histogram should be uniform for an efficient encryption. Also, the histograms of encrypted color RGB components should be different from their corresponding original color RGB components. Experimental histogram tests of the original/encrypted RGB components of colored Lena, House and Sailboat images using optical DRPE are shown in Fig. 3-5. The obtained results show that the histograms of encrypted RGB components for Lena, House and Sailboat images were completely different from corresponding histograms of their original color RGB components. The encrypted RGB components histogram for color Lena, House and Sailboat images using optical DRPE are quite uniform. So, the optical DRPE has the ability to resist any histogram based attack.

$\begin{array}{llll}\text { Color } & \text { Color } & \text { Color } & \begin{array}{l}\text { Decrypted } \\ \text { cipherimage }\end{array} \\ \text { Image } & \text { plainimage } & \text { Plainimage } & \text { pls }\end{array}$

Red
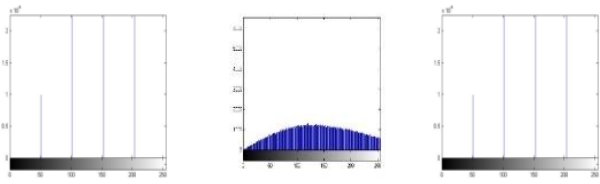

Green
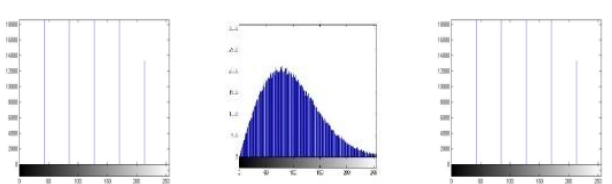

Blue
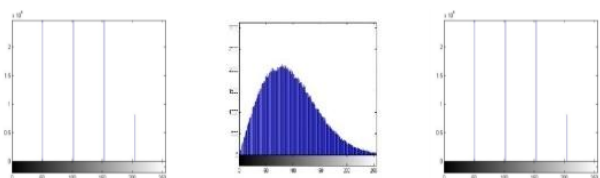

Fig. 3: RGB components Histogram of encrypted/decrypted color Lena image using optical DRPE

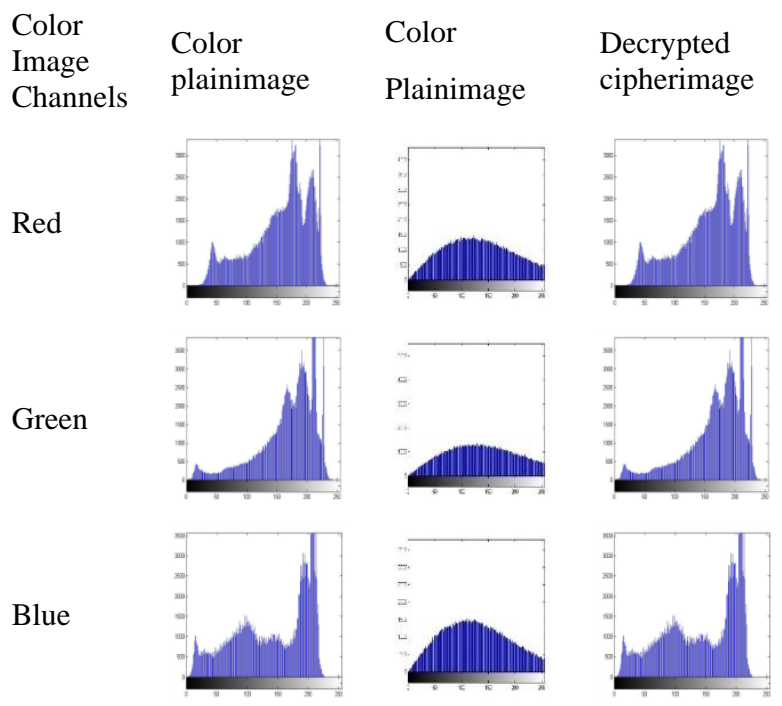

Fig. 4: RGB components Histogram of encrypted/decrypted color House image using optical DRPE

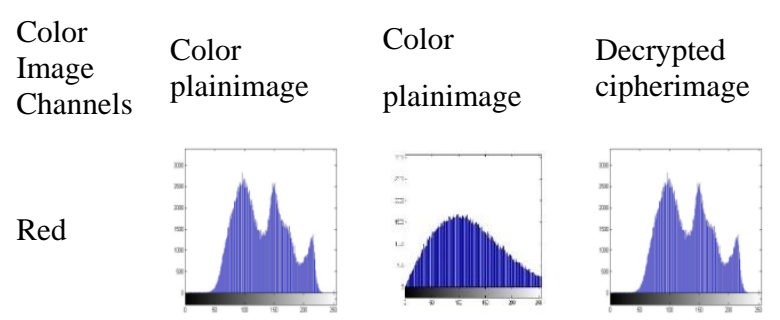


Green
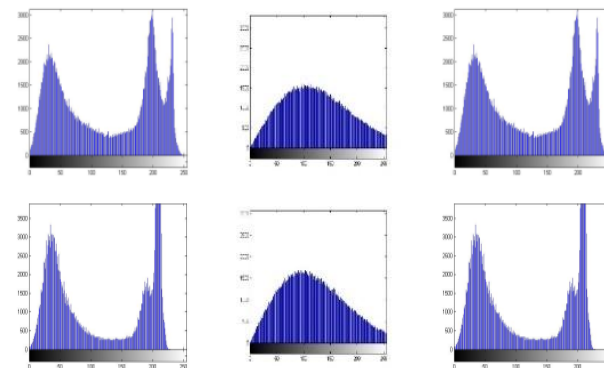

Fig. 5: RGB components Histogram of encrypted/decrypted color Sailboat image using optical DRPE

\subsection{Encryption Quality Tests}

The encryption quality can be estimated using several estimations like correlation coefficient, histogram deviation and irregular deviation.

The correlation coefficients $r$ is estimated among original image $\mathrm{OI}\left(\mathrm{x}_{\mathrm{i}}, \mathrm{y}_{\mathrm{j}}\right)$ and encrypted image $\mathrm{EI}\left(\mathrm{x}_{\mathrm{i}}, \mathrm{y}_{\mathrm{j}}\right) \quad \mathrm{RGB}$ components as [11-12]:

$\mathrm{r}(\mathrm{OI}, \mathrm{EI})=\frac{\mathrm{E}\{(\mathrm{EI}-\mathrm{E}(\mathrm{EI})) \cdot(\mathrm{OI}-\mathrm{E}(\mathrm{OI}))\}}{\left.\sqrt{\mathrm{E}\left\{[\mathrm{EI}-\mathrm{E}(\mathrm{EI})]^{2}\right\}} \sqrt{\mathrm{E}\left\{[\mathrm{OI}-\mathrm{E}(\mathrm{OI})]^{2}\right.}\right\}}$,

where $E\{\}$ is expectation operator. Small $\mathbf{r}_{\text {indicates high }}$ difference between the original image $\mathrm{OI}\left(\mathrm{x}_{\mathrm{i}}, \mathrm{y}_{\mathrm{j}}\right)$ and encrypted image $\mathrm{EI}\left(\mathrm{x}_{\mathrm{i}}, \mathrm{y}_{\mathrm{j}}\right)$ RGB components.

The ID measure estimates the encryption efficiency in terms of how much irregular is the difference caused by encryption. The ID can be estimated as [13-15]:

$I D(I, E)=\frac{\left|\sum_{i=0}^{255} h_{d}(i)\right|}{M x N}$,

$h_{d}(i)=\left|h(i)-M_{h}\right|$,

where $\mathrm{h}(\mathrm{i})$ is cipherimage histogram and $M_{h}$ is average uniform histogram for encrypted image. Small ID values indicate good encryption quality.

The HD measure estimates the encryption quality by how it enlarges the difference among the original image $\mathrm{OI}\left(\mathrm{x}_{\mathrm{i}}, \mathrm{y}_{\mathrm{j}}\right)$ and encrypted image $\mathrm{EI}\left(\mathrm{x}_{\mathrm{i}}, \mathrm{y}_{\mathrm{j}}\right)$ RGB components. The HD can be calculated as [13-15]:

$H D(I, E)=\frac{\left|\sum_{i=0}^{255} d(i)\right|}{M x N}$,

where $d(i)$ is absolute difference among the original image $\mathrm{OI}\left(\mathrm{x}_{\mathrm{i}}, \mathrm{y}_{\mathrm{j}}\right)$ and encrypted image $\mathrm{EI}\left(\mathrm{x}_{\mathrm{i}}, \mathrm{y}_{\mathrm{j}}\right)$ RGB components. The variables $M$ and $N$ represent image dimensions. High $H D$ values ensure large difference between the original image $\mathrm{OI}\left(\mathrm{x}_{\mathrm{i}}, \mathrm{y}_{\mathrm{j}}\right)$ and encrypted image $\mathrm{EI}\left(\mathrm{a}_{\mathrm{i}}, \mathrm{b}_{\mathrm{j}}\right)$ RGB components.

Table 1 shows the Correlation coefficients, Irregular Deviation, and histogram deviation metrics of encrypted RGB components for color Lena, House and sailboat using Optical DRPE. The resulted correlation coefficients, Irregular and histogram deviations metrics shown in Table 1 ensure good encryption quality of optical DRPE.
Table 1: Correlation coefficients, Irregular deviation, and histogram deviation metrics for encrypted RGB components for colored Lena, House and sailboat using Optical DRPE

\begin{tabular}{|l|l|l|l|l|}
\hline \multirow{4}{*}{$\begin{array}{l}\text { Color } \\
\text { Image }\end{array}$} & $\begin{array}{l}\text { Security } \\
\text { Metrics }\end{array}$ & \multicolumn{2}{|l|}{ Optical DRPE } \\
\cline { 3 - 5 } & Led & Green & Blue \\
\hline \multirow{4}{*}{ House } & $\mathrm{r}_{\mathrm{xy}}$ & -0.0034 & $7.830 \mathrm{e}-004$ & -0.002 \\
\cline { 2 - 5 } & $\mathrm{D}_{\mathrm{H}}$ & 1.7053 & 1.07053 & 1.9605 \\
\cline { 2 - 5 } & $\mathrm{D}_{\mathrm{I}}$ & 0.7120 & 0.7094 & 0.9852 \\
\hline \multirow{4}{*}{ Sailboat } & $\mathrm{r}_{\mathrm{xy}}$ & 0.0029 & 0.0015 & $1.997 \mathrm{e}-004$ \\
\cline { 2 - 5 } & $\mathrm{D}_{\mathrm{H}}$ & 0.6495 & 0.8097 & 0.5952 \\
\cline { 2 - 5 } & $\mathrm{D}_{\mathrm{I}}$ & 0.7230 & 0.7109 & 0.6583 \\
\cline { 2 - 5 } & $\mathrm{r}_{\mathrm{xy}}$ & -0.0019 & 0.0028 & -0.0024 \\
\cline { 2 - 5 } & $\mathrm{D}_{\mathrm{H}}$ & 0.4942 & 0.8075 & 0.9772 \\
\hline & $\mathrm{D}_{\mathrm{I}}$ & 0.8334 & 0.5504 & 0.5685 \\
\hline
\end{tabular}

\subsection{Information Entropy Measure}

The information entropy test is utilized for estimating encrypted R, G, and B components information amount. The information entropy measure may be estimated as [16]

$\mathrm{E}(\mathrm{S})=\sum_{\mathrm{i}=1}^{2 \mathrm{~N}_{-1}}\left(\mathrm{~S}_{\mathrm{i}}\right) \log _{2} \frac{1}{\mathrm{P}\left(\mathrm{S}_{\mathrm{i}}\right)}$,

where $\mathrm{E}(\mathrm{S})$, and $\mathrm{P}\left(\mathrm{S}_{\mathrm{i}}\right)$ are the entropy and the occurrence must be 8 bits.

The objective of information entropy measure is to estimate information amount of encrypted RGB components for colored Lena, House and sailboat using Optical DRPE. Table 2 gives the information entropy estimates of encrypted RGB components for colored Lena, House and sailboat using Optical DRPE. The obtained results demonstrated that the information entropy values of encrypted RGB components for colored Lena, House and sailboat are near the optimal information entropy estimate of 8 bits.

Table 2: Information entropy metric of original/encrypted RGB components for colored Lena, House and sailboat using Optical DRPE

\begin{tabular}{|l|l|l|l|l|l|l|}
\hline \multirow{2}{*}{ Image } & \multicolumn{3}{|c|}{ Colored Plainimage } & \multicolumn{2}{|l|}{$\begin{array}{l}\text { Encrypted } \\
\text { Cipherimage with DRPE } \\
\text { Optical Encryption }\end{array}$} \\
\cline { 2 - 7 } & Red & $\begin{array}{l}\text { Gree } \\
\mathrm{n}\end{array}$ & Blue & Red & Green & Blue \\
\hline Lena & $\begin{array}{l}1.97 \\
3\end{array}$ & 1.973 & $\begin{array}{l}1.62 \\
8\end{array}$ & $\begin{array}{l}7.309 \\
9\end{array}$ & $\begin{array}{l}7.310 \\
9\end{array}$ & $\begin{array}{l}7.589 \\
5\end{array}$ \\
\hline House & $\begin{array}{l}7.41 \\
6\end{array}$ & 7.229 & $\begin{array}{l}7.43 \\
5\end{array}$ & $\begin{array}{l}7.597 \\
0\end{array}$ & $\begin{array}{l}7.450 \\
5\end{array}$ & $\begin{array}{l}7.672 \\
7\end{array}$ \\
\hline $\begin{array}{l}\text { Sailboa } \\
\mathrm{t}\end{array}$ & $\begin{array}{l}7.31 \\
2\end{array}$ & 7.643 & $\begin{array}{l}7.21 \\
4\end{array}$ & $\begin{array}{l}7.750 \\
4\end{array}$ & $\begin{array}{l}7.732 \\
0\end{array}$ & $\begin{array}{l}7.752 \\
0\end{array}$ \\
\hline
\end{tabular}

\subsection{Differential Measure}

Differential measure is carried out to study the impact of one pixel changing in two plainimages on their respected cipherimages with optical DRPE. The differential test is 
evaluated using the number of pixels changing rate (NPCR) and the unified averaging changing intensity (UACI) [40].

The $\mathrm{NPCR}_{\mathrm{R}, \mathrm{G}, \mathrm{B}}$ may be computed as [17-20]:

$\mathrm{NPCR}_{\mathrm{R}, \mathrm{G}, \mathrm{B}}\left(\mathrm{C}^{1}, \mathrm{C}^{2}\right)=\frac{\sum_{\mathrm{i}, \mathrm{j}} \mathrm{D}_{\mathrm{R}, \mathrm{G}, \mathrm{B}}\left(\mathrm{a}_{\mathrm{i}}, \mathrm{b}_{\mathrm{j}}\right)}{\mathrm{N}} \times 100 \%$,

where $\mathrm{N}$ is image pixels number and $\mathrm{D}_{\mathrm{R}, \mathrm{G}, \mathrm{B}}\left(\mathrm{a}_{\mathrm{i}}, \mathrm{b}_{\mathrm{j}}\right)$ is as:

$D_{R, G, B}\left(C^{1}, C^{2}\right)= \begin{cases}0, & C_{R, G, B}^{1}\left(a_{i}, b_{j}\right)=C_{R, G, B}^{2}\left(a_{i}, b_{j}\right) \\ 1, & C_{R, G, B}^{1}\left(a_{i}, b_{j}\right) \neq C_{R, G, B}^{2}\left(a_{i}, b_{j}\right)\end{cases}$

where $C_{R, G, B}^{1}\left(a_{i}, b_{j}\right)$ and $C_{R, G, B}^{2}\left(a_{i}, b_{j}\right)$ are the corresponding color RGB components in the two color cipherimages $C^{1}\left(a_{i}, b_{j}\right)$ and $\mathrm{C}^{2}\left(\mathrm{a}_{\mathrm{i}}, \mathrm{b}_{\mathrm{j}}\right)$, respectively.

The $\mathrm{UACI}_{\mathrm{R}, \mathrm{G}, \mathrm{B}}$ can be defined as [17-20]:

$\operatorname{UACI}_{R, G, B}\left(\mathrm{C}^{1}, \mathrm{C}^{2}\right)=\frac{1}{N}\left[\sum_{i, j} \frac{\left|\mathrm{C}_{\mathrm{R}, \mathrm{G}, \mathrm{B}}^{1}\left(\mathrm{a}_{\mathrm{i}}, \mathrm{b}_{\mathrm{j}}\right)-\mathrm{C}_{\mathrm{R}, \mathrm{G}, \mathrm{B}}^{2}\left(\mathrm{a}_{\mathrm{i}}, \mathrm{b}_{\mathrm{j}}\right)\right|}{255}\right] \times 100 \%$,

The NPCR/UACI experimental tests are illustrated in Table 3. The experimental tests ensure the sensitivity of optical DRPE regarding small modification in color plainimages RGB components.

Table 3: NPCR/UACI of encrypted RGB components for color Lena, House and sailboat using Optical DRPE

\begin{tabular}{|l|l|l|l|l|}
\hline \multirow{3}{*}{ Image } & \multirow{2}{*}{ Metric } & \multicolumn{3}{|l|}{ Encrypted color images with Optical } \\
\cline { 3 - 5 } & & Red & Green & Blue \\
\hline \multirow{3}{*}{ Lena } & NPCR & 97.7814 & 97.7921 & 99.3645 \\
\cline { 3 - 5 } & UACI & 0 & 0 & 0 \\
\hline \multirow{3}{*}{ House } & NPCR & 99.5644 & 99.6082 & 99.6151 \\
\cline { 2 - 5 } Sailboat & UACI & 0 & 0 & 0 \\
\hline \multirow{2}{*}{} & NPCR & 99.5125 & 99.6452 & 99.6742 \\
\cline { 2 - 5 } & UACI & 0 & 0 & 0 \\
\hline
\end{tabular}

\subsection{Noise Resistance Test}

The optical DRPE resistance regarding noise attacks is tested in the decryption phase using peak signal to noise ratio (PSNR), SSIM and FSIM. The employed noises are salt and pepper, additive white Gaussian noise (AWGN), and speckle noises, respectively. The PSNR is employed to test the quality of decrypted RGB components.

The PSNR may be estimated as [21-22]:

$\operatorname{PSNR}(\mathrm{OI}, \mathrm{EI})=10 \log _{10} \frac{(255)^{2}}{\operatorname{MSE}(\mathrm{OI}, \mathrm{EI})}$

The SSIM is utilized to test quality of decrypted image. The SSIM is computed as [23-26]:

$$
\operatorname{SSIM}(\mathrm{x}, \mathrm{y} \mid \mathrm{w})=\frac{\left(2 \overline{\mathrm{w}}_{\mathrm{x}} \overline{\mathrm{w}}_{\mathrm{y}}+\mathrm{C}_{1}\right)\left(2 \sigma_{\mathrm{w}_{\mathrm{x}} \mathrm{w}_{\mathrm{y}}}+\mathrm{C}_{2}\right)}{\left(\overline{\mathrm{w}}_{\mathrm{x}}^{2}+\overline{\mathrm{w}}_{\mathrm{y}}^{2}+\mathrm{C}_{1}\right)\left(\sigma_{\mathrm{w}_{\mathrm{x}}}^{2}+\sigma_{\mathrm{w}_{\mathrm{y}}}^{2}+\mathrm{C}_{2}\right)}
$$

where, $\mathrm{C} 1, \mathrm{C} 2$ are minor constants, $\overline{\mathrm{w}}_{\mathrm{x}}$ and $\overline{\mathrm{w}}_{\mathrm{y}}$ are average of $\mathrm{w}_{\mathrm{x}}$ and $\mathrm{w}_{\mathrm{y}}$ regions, respectively. $\Sigma_{\mathrm{w}_{\mathrm{x}}}^{2}$ is the region $\mathrm{w}_{\mathrm{x}}$ variance and $\sigma_{\mathrm{w}_{\mathrm{x}} \mathrm{w}_{\mathrm{y}}}$ is two regions covariance among $\mathrm{w}_{\mathrm{x}}$ and $\mathrm{w}_{\mathrm{y}}$. High SSIM values mean perfect resistance against noise.

The FSIM is utilized to test the decrypted image quality. The FSIM is computed as [23-26]:

$\mathrm{FSIM}=\frac{\sum_{\mathrm{x} \in \Omega} \mathrm{S}_{\mathrm{L}}(\mathrm{x}) \cdot \mathrm{PC}_{\mathrm{m}}(\mathrm{x})}{\sum_{\mathrm{x} \in \Omega} \mathrm{PC}_{\mathrm{m}}(\mathrm{x})}$

where $\Omega$ is image spatial domain, $\mathrm{S}_{\mathrm{L}}(\mathrm{x})$ is overall similarity among two images and $\mathrm{PC}_{\mathrm{m}}(\mathrm{x})$ is phase congruency. High FSIM values mean perfect resistance against noise. The noise immunity results of decrypted RGB components for color Lena, House and sailboat using Optical DRPE with AWGN with variance $=0.01,0.05$ and 0.1 , speckle noise with variance $=0.01,0.05$ and 0.1 , and salt $\&$ pepper with density $=0.01,0.05$ and 0.1 are shown in Tables 4-6 and Figs. 6-8. The noise resistance results using PSNR, SSIM and FSIM demonstrated the efficiency of the optical DRPE with respect to all the three different types of noise like AWGN with variance $=0.01,0.05$ and 0.1 , speckle noise with variance $=$ $0.01,0.05$ and 0.1 , and salt $\&$ pepper with variance $=0.01$, 0.05 and 0.1 .

Table 4: PSNR of deciphered RGB components for colored Lena, House and sailboat using Optical DRPE in the presence of AWGN, Salt \& peppers, and Speckle noises

\begin{tabular}{|c|c|c|c|c|c|c|c|c|c|c|}
\hline \multirow{3}{*}{ Image } & \multirow{3}{*}{ Components } & \multicolumn{9}{|l|}{ PSNR } \\
\hline & & \multicolumn{3}{|c|}{ AWGN variance } & \multicolumn{3}{|c|}{ Salt \&peppers density } & \multicolumn{3}{|c|}{ Speckle density } \\
\hline & & 0.01 & 0.05 & 0.1 & 0.01 & 0.05 & 0.1 & 0.01 & 0.05 & 0.1 \\
\hline \multirow{3}{*}{ Lena } & Red & 2.8390 & 2.8390 & 2.8391 & 2.8392 & 2.8392 & 2.8392 & 2.8387 & 2.8381 & 3.8375 \\
\hline & Green & 7.3240 & 7.3239 & 7.3238 & 7.3238 & 7.3237 & 7.3238 & 7.3235 & 7.3231 & 7.3228 \\
\hline & Blue & 7.4922 & 7.4919 & 7.4919 & 7.4918 & 7.4919 & 7.4923 & 7.4916 & 7.4914 & 7.4913 \\
\hline \multirow{3}{*}{ House } & Red & 3.8936 & 3.8936 & 3.8937 & 3.8938 & 3.8938 & 3.8938 & 3.8932 & 3.8926 & 3.8922 \\
\hline & Green & 3.8937 & 3.2914 & 3.2915 & 3.2916 & 3.2916 & 3.2915 & 3.3911 & 3.290 & 3.2901 \\
\hline & Blue & 4.3604 & 4.3605 & 4.3606 & 4.3607 & 4.3606 & 4.3604 & 4.3600 & 4.3593 & 4.3589 \\
\hline Sailboat & Red & 5.3763 & 5.3762 & 5.3762 & 5.3763 & 5.3762 & 5.3763 & 5.3758 & 5.3752 & 5.3749 \\
\hline
\end{tabular}




\begin{tabular}{|l|l|l|l|l|l|l|l|l|l|l|}
\hline & Green & 4.8409 & 4.8410 & 4.8411 & 4.8412 & 4.8409 & 4.8405 & 4.8395 & 4.8395 & 4.8385 \\
\cline { 2 - 10 } & Blue & 5.3506 & 5.3506 & 5.3507 & 5.3508 & 5.3502 & 5.3502 & 5.3502 & 5.3492 & 5.3485 \\
\hline
\end{tabular}

Table 5: SSIM of deciphered RGB components for colored Lena, House and sailboat using Optical DRPE in the presence of AWGN, Salt \& peppers, and Speckle noises

\begin{tabular}{|c|c|c|c|c|c|c|c|c|c|c|}
\hline \multirow{3}{*}{ Image } & & \multicolumn{9}{|c|}{ Feature Similarity Index (FSIM) } \\
\hline & & \multicolumn{3}{|c|}{ AWGN variance } & \multicolumn{3}{|c|}{ Salt \&peppers density } & \multicolumn{3}{|c|}{ Speckle density } \\
\hline & & 0.01 & 0.05 & 0.1 & 0.01 & 0.05 & 0.1 & 0.01 & 0.05 & 0.1 \\
\hline \multirow{3}{*}{ Lena } & Red & 0.0027 & 0.0027 & 0.0027 & 0.0027 & 0.0027 & 0.0027 & 0.0026 & 0.0026 & 0.0026 \\
\hline & Green & 0.0043 & 0.0041 & 0.0041 & 0.0041 & 0.0045 & 0.0048 & 0.0041 & 0.0043 & 0.0045 \\
\hline & Blue & 0.0035 & 0.0034 & 0.0034 & 0.0034 & 0.0035 & 0.0036 & 0.0034 & 0.0034 & 0.0035 \\
\hline \multirow{3}{*}{ House } & Red & 0.0029 & 0.0029 & 0.0029 & 0.0029 & 0.0030 & 0.0030 & 0.0029 & 0.0029 & 0.0028 \\
\hline & Green & 0.0029 & 0.0029 & 0.0029 & 0.0029 & 0.0029 & 0.0029 & 0.0028 & 0.0028 & 0.0028 \\
\hline & Blue & 0.0036 & 0.0035 & 0.0035 & 0.0036 & 0.0036 & 0.0036 & 0.0035 & 0.0035 & 0.0035 \\
\hline \multirow{3}{*}{ Sailboat } & Red & 0.0035 & 0.0035 & 0.0035 & 0.0035 & 0.0035 & 0.0036 & 0.0035 & 0.0034 & 0.0035 \\
\hline & Green & 0.0043 & 0.0042 & 0.0042 & 0.0042 & 0.0043 & 0.0045 & 0.0042 & 0.0044 & 0.0045 \\
\hline & Blue & 0.0056 & 0.0055 & 0.0054 & 0.0054 & 0.0057 & 0.0060 & 0.0055 & 0.0057 & 0.0059 \\
\hline
\end{tabular}

Table 6: FSIM of deciphered RGB components for colored Lena, House and sailboat using Optical DRPE in the presence of AWGN, Salt \& peppers, and Speckle noises

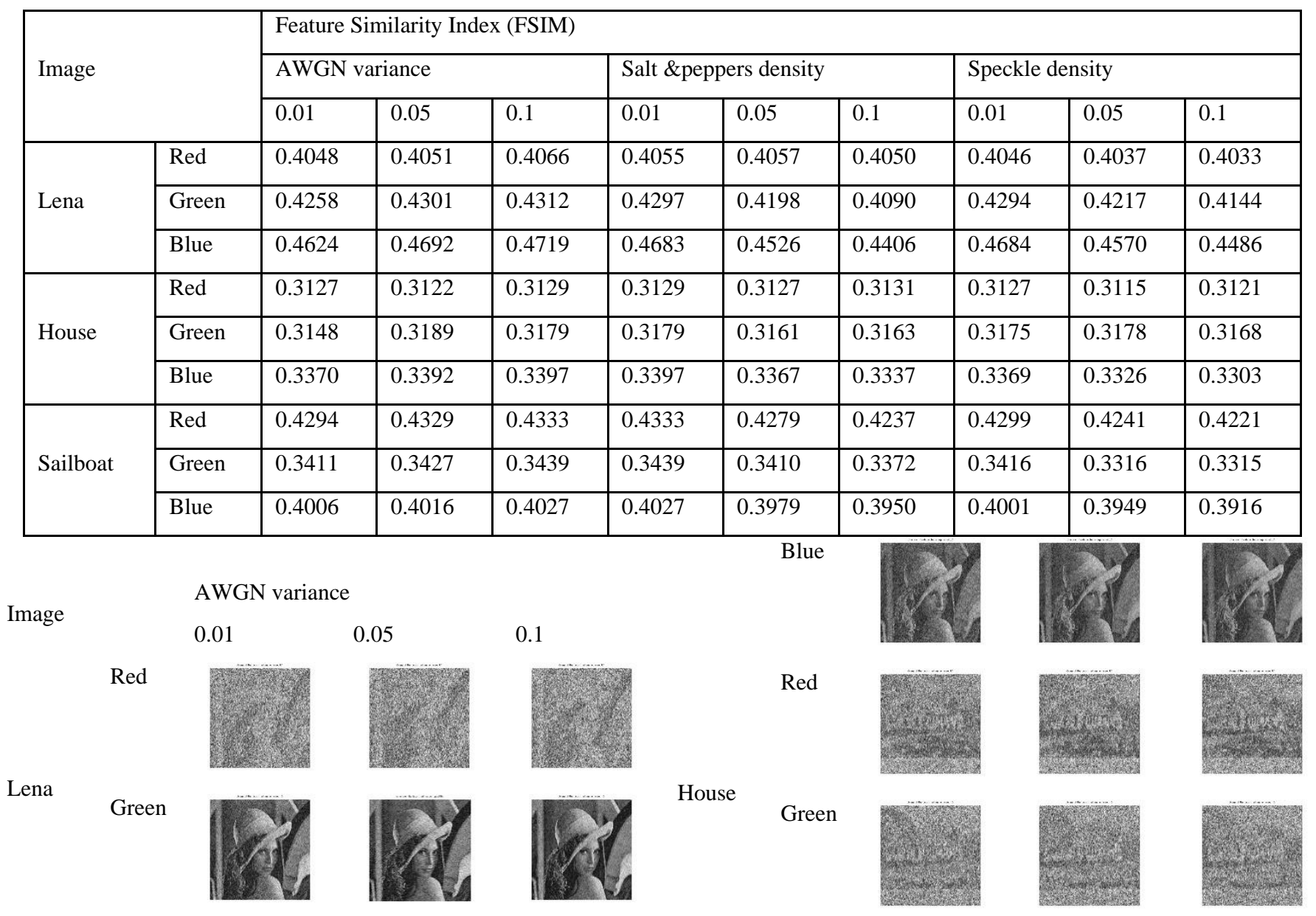



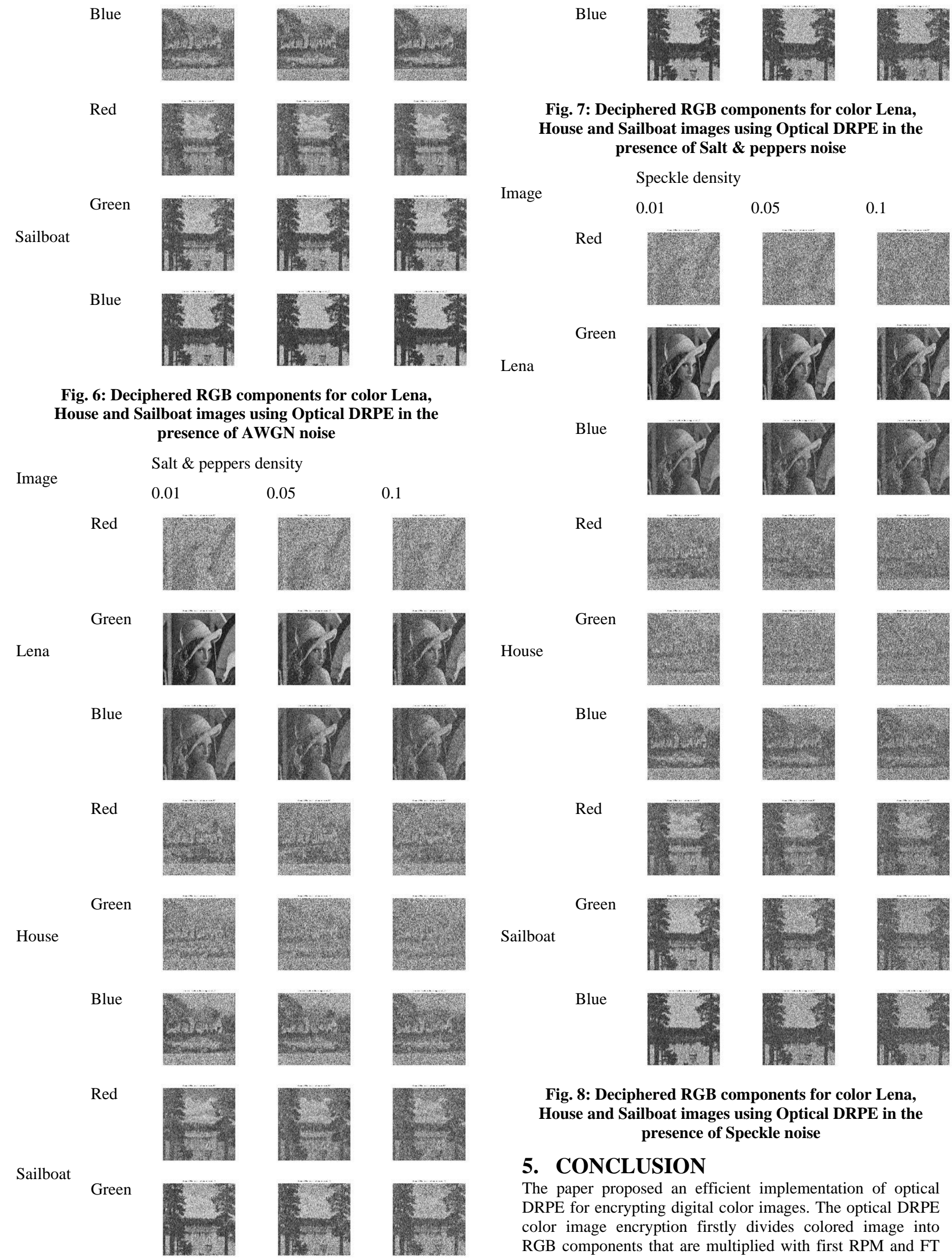

Fig. 7: Deciphered RGB components for color Lena, House and Sailboat images using Optical DRPE in the presence of Salt $\&$ peppers noise Speckle density

Image

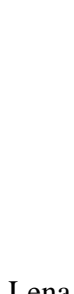

Lena
0.01

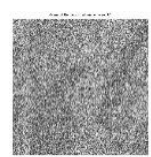

Green

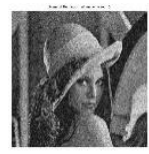

Blue

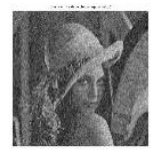

Red

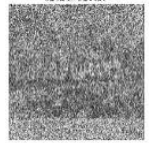

0.05

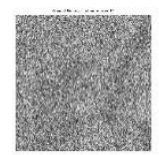

0.1

Red
Green

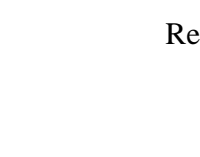

Green

Blue
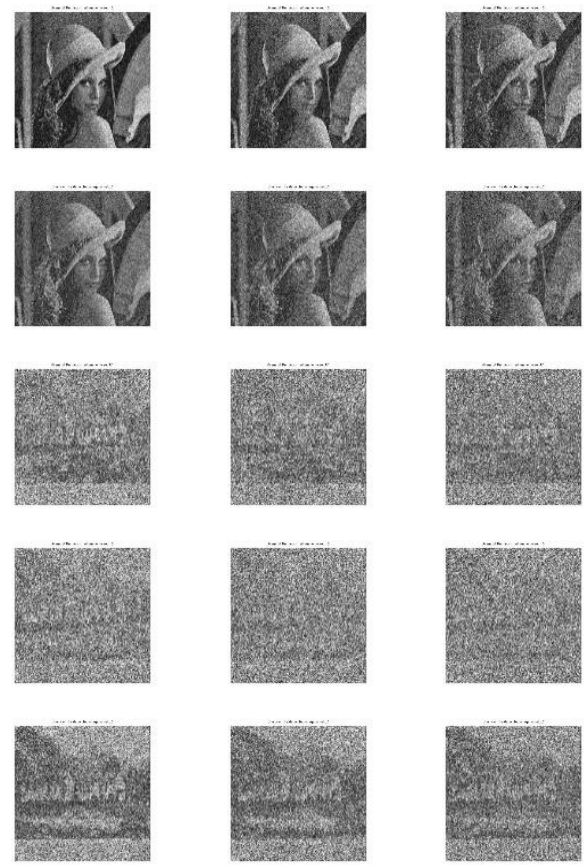

Red
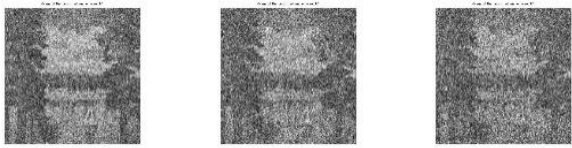

Sailboat

Green
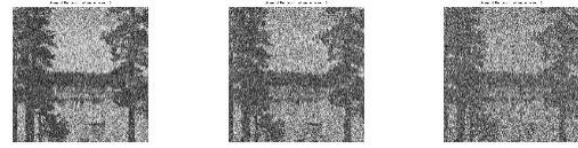

Blue
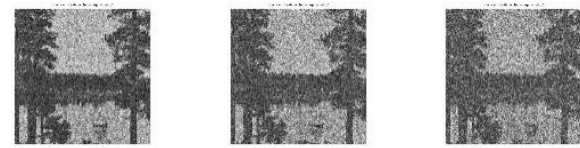

Fig. 8: Deciphered RGB components for color Lena, House and Sailboat images using Optical DRPE in the presence of Speckle noise

\section{CONCLUSION}

The paper proposed an efficient implementation of optical DRPE for encrypting digital color images. The optical DRPE color image encryption firstly divides colored image into RGB components that are multiplied with first RPM and FT transformed. The transformed RGB components are secondly multiplied by another RPM and secondly inverse FT 
transformed. The optical DRPE color image decryption divides the encrypted colored image into RGB components that are FT transformed and multiplied with the second RPM conjugate. The transformed RGB components are gain multiplied by the first RPM conjugate and secondly inverse FT transformed. A set of tests are examined for studying the optical DRPE color image encryption. Test demonstrated efficiency of the optical DRPE encryption applied to color images.

\section{REFERENCES}

[1] S. Kishk and B. Javidi, "Information hiding technique with double phase encoding"applied optics, 41, 54625470, 2002.

[2] Z. Liu Z, S. Li, W. Liu, Y. Wang, S. Liu, "Image encryption algorithm by using fractional Fourier transform and pixel scrambling operation based on double random phase encoding," Opt. Lasers Eng., vol. 51, pp. 8-14, 2013.

[3] M. R. Abuturab, "Color image security system based on discrete Hartley transform in gyrator transform domain, " Opt. Lasers Eng., vol. 51, pp. 317-324, 2013.

[4] Liu Z, Dai J, Sun X, Liu S., "Color image encryption by using the rotation of color vector in Hartley transform domains," Opt. Laser Eng., vol. 48, pp. 800-805, 2010.

[5] P. Refregier and B. Javidi, "Optical image encryption based on input plane and Fourier plane random encoding" Opt. Lett., vol. 20, pp. 767-769, 1995.

[6] R. Tao, J. Lang, Y. Wang, "Optical image encryption based on the multipleparameter fractional Fourier transform," Opt. Lett. 33, pp. 581-583, 2008.

[7] Z. Liu, S. Liu, "Double image encryption based on iterative fractional Fourier transform," Opt. Commun. vol. 275, pp. 324-329, 2007.

[8] Y. Frauel, A. Castro, T. J. Naughton, B. Javidi, "Security analysis of optical encryption," Proc SPIE, vol. 5986, pp. 25-34, 2005.

[9] Y. Frauel, A. Castro, T. J. Naughton, B. Javidi, "Resistance of the double random phase encryption against various attacks," Opt. Express, vol. 15, pp. 10253-10265, 2007.

[10] X. Peng, P. Zhang, H. Wei, B. Yu, "Known-plaintext attack on optical encryption based on double random phase keys," Opt. Lett., vol. 31, pp. 1044-1046, 2006.

[11] Ensherah A. Naeem, Mustafa M. Abd Elnaby, Naglaa F. Soliman, Alaa M. Abbas, Osama S. Faragallah, Noura Semary, Mohiy M. Hadhoud, Saleh A. Alshibeili, and Fathi E. Abd El-Samie, "Efficient Implementation of Chaotic Image Encryption in Transform Domains," Journal of Systems and Software, vol. 97, pp. 118-127, 2014.

[12] Z. Liu, Y. Zhang, W. Liu, F. Meng, Q. Wu, S. Liu, Optical color image hiding scheme based on chaotic mapping and Hartley transform, Optics and Lasers in Engineering, 51, pp. 967-972, 2013.

[13] Ensherah A. Naeem, Mustafa M. AbdElnaby, Hala S. Elsayed, Fathi E. Abd El-Samie, and Osama S. Faragallah, "Wavelet Fusion for Encrypting Images with a Few Details," Computers and Electrical Engineering, vol. 54, pp. 450-470, 2016.
[14] Heba M. Elhoseny, Hossam E. H. Ahmed, Alaa M. Abbas, Hassan B. Kazemian, Osama S. Faragallah, Sayed M. El-Rabaie, Fathi E. Abd El-Samie, "Chaotic encryption of images in the fractional Fourier transform domain using different modes of operation," Signal, Image and Video Processing Journal "Springer-Verlag" ISSN 1863-1703, 2013, DOI 10.1007/s11760-013-0490$\mathrm{x}$

[15] Elsayed M. Elshamy, Sayed El-Rabaie, Osama S. Faragallah, Osama Elshakankiry, Fathi. E. Abd ElSamie, Hala S. El-sayed, and S. F. El-Zoghdy, "Efficient Audio Cryptosystem based on Chaotic Maps and Double Random Phase Encoding," International Journal of Speech Technology, vol. 18(4), pp. 619-631, 2015, Springer.

[16] Osama S. Faragallah, "An Enhanced Chaotic Key-Based RC5 Block Cipher Adapted to Image Encryption," International Journal of Electronics, vol. 99(7), pp. 925943, Taylor \& Francis, 2012.

[17] Joshi M, Shakher C, Singh K., "Logarithms-based RGB image encryption in the fractional Fourier domain: a nonlinear approach," Opt. Lasers Eng., vol. 47, pp. 721-727, 2009.

[18] Liu Z, Xu L, Liu T, Chen H, Li P, Lin C, et al., "Color image encryption by using Arnold transform and colorblend operation in discrete cosine transform domains," Opt. Commun. vol. 284, pp. 123-128, 2011.

[19] Chen W, Chen X, Sheppard CJR. "Optical color-image encryption and synthesis using coherent diffractive imaging in the Fresnel domain," Opt. Express, vol. 20, pp. 3853-3865, 2012.

[20] Q. Guo, Z. Liu, S. Liu, Color image encryption by using Arnold and discrete fractional random transforms in IHS space, Optics and Lasers in Engineering, 48, 1174-1181, 2010.

[21] Hu Y J, Lee H K, Chen K Y.D. "Difference expansion based reversible data hiding using two embedding direction, " IEEE Trans on Multimedia, vol. 10(8), pp. $1500-1512,2008$

[22] T. Narasimmalou, R. Allen Joseph, "Discrete Wavelet Transform Based Steganography for Transmitting Images," Science And Management (ICAESM), pp. 370375, IEEE, Villupuram, India, March 30-31, 2012.

[23] Z. Liu, Y. Zhang, S. Li, W. Liu, W. Liu, Y. Wang, S. Liu, Double image encryption scheme by using random phase encoding and pixel exchanging in the gyrator transform domains, Optics and Laser Technology, vol. 47, pp. 152-158, 2012.

[24] L. Zhang,D. X. Mou, FSIM: A Feature Similarity Index for Image Quality Assessment, Image Processing, IEEE Transactions on, 20 (8), 2378-2386, 2011.

[25] G. N. Raut, P. L. Paikrao, D. S. Chaudhari, A Study of Quality Assessment Techniques For Fused Images, IJITEE, 2 (4) , 2013.

[26] Osama S. Faragallah, "Optical Double Color Image Encryption Scheme in the Fresnel-based Hartley Domain Using Arnold Transform and Chaotic Logistic Adjusted Sine Phase Masks," Optical and Quantum Electronics, vol. 50(3):118, pp. 1-27, 2018. 